\title{
Investigation of a spatiotemporal cluster of verotoxin- producing Escherichia coli O157 infections in eastern England in 2007
}

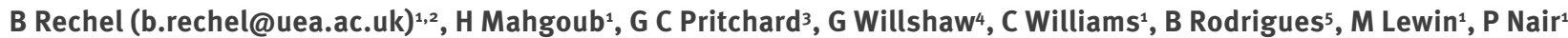

1. Norfolk, Suffolk and Cambridgeshire Health Protection Unit, Thetford Community Healthy Living Centre, Thetford, United Kingdom

2. Norwich Medical School, University of East Anglia, Norwich, United Kingdom

3. Veterinary Laboratories Agency, Bury St Edmunds, Suffolk, United Kingdom

4. Laboratory of Gastrointestinal Pathogens, Health Protection Agency, London, United Kingdom

5. National Health Service Sutton and Merton, Wimbledon, London, United Kingdom

Citation style for this article:

Rechel B, Mahgoub H, Pritchard GC, Willshaw G, Williams C, Rodrigues B, Lewin M, Nair P. Investigation of a spatiotemporal cluster of verotoxin-producing Escherichia coli 0157 infections in eastern England in 2007.

Euro Surveill. 2011;16(28):pii=19916. Available online: http://www.eurosurveillance.org/ViewArticle.aspx?Articleld=19916

An outbreak of verotoxin-producing Escherichia coli 0157 (VTEC 0157) infections linked to an open farm occurred in eastern England in April and May 2007. This paper describes the investigation and highlights the importance of multidisciplinary collaboration for successful control of such outbreaks. There was a temporal cluster of 12 confirmed symptomatic cases of VTEC 0157 and one asymptomatic carrier, from five families. The investigation revealed that four of these cases formed part of an outbreak involving two families who visited an open farm. The phenotypic and genotypic characteristics of the isolates from the two families and the putative farm animal contacts were indistinguishable, indicating that the animals were the source of the primary infections. No epidemiological link could be established between the remaining three families affected and the open farm or people having visited the farm. Control measures included improved hand washing facilities on the farm, information for visitors and staff, restricted access and suspended petting and feeding of animals, and thorough cleaning and disinfection of affected areas.

\section{Introduction}

The most important strains of verotoxin (VT)producing Escherichia coli (VTEC) that cause diarrhoeal illness in the United Kingdom (UK) belong to serogroup $0_{157}$ (VTEC 0157) [1]. They produce VT1, VT2 or both toxins and are differentiated by phage typing and DNA-based techniques [2]. E. coli 0157 is an important, although relatively uncommon, cause of infectious gastroenteritis in England and Wales. Between 2000 and 2008 the number of reference laboratory-confirmed isolates of VTEC $0_{157}$ in England and Wales ranged from 595 in 2002 to 1,034 in 2009 and 793 in 2010 [3]. Of 948 strains in 2008, 73 came from the east of England [4]. In comparison, 55,609 Campylobacter strains were isolated in England and Wales in the same year [5]. Several outbreaks of VTEC 0157 have been recently reported in the UK [6-9]. Healthy domesticated animals such as cattle, sheep and goats are the natural reservoir for VTEC $[1,10]$. Spread to humans occurs through contaminated food or water, person-to-person spread or by direct and indirect contact with infected animals and their faeces [1].

The disease severity ranges from mild and self-limiting diarrhoea to serious and sometimes fatal illness, especially in young children or elderly people [11]. Haemorrhagic colitis develops in about half of the identified VTEC 0157 cases in England and Wales [12]. Haemolytic uraemic syndrome (HUS) complicates about $2-7 \%$ of all cases of VTEC 0157 gastroenteritis $[13,14]$. Its manifestations include renal failure, haemolytic anaemia, thrombocytopenia, and central nervous system symptoms. HUS has a fatal outcome in up to $17 \%$ of cases [15-17], while a substantial proportion of the survivors suffer renal or other long term residual impairments [18].

Between 18 April and 3 May 2007, the Norfolk, Suffolk and Cambridgeshire (NSC) Health Protection Unit (HPU) Norfolk office was notified of eleven cases of presumptive $E$. coli 0157 infection and one asymptomatic carrier from four families in Norfolk. This represented an unusually high number of cases for this region within a period of a few weeks. The index case from the first family (A) had visited an open farm in eastern England. On 1 May 2007, the HPU was notified of a child from Lincolnshire (Family B) who was hospitalised with $E$. coli 0157 gastroenteritis and HUS, and had visited the same farm. Norfolk and Lincolnshire are neighbouring counties. This report presents the epidemiological and microbiological investigations of this spatiotemporal cluster of VTEC 0157 infections. 


\section{Methods}

\section{Epidemiological investigations}

A primary case was defined as the first person in a household with gastrointestinal illness (three or more loose stools in a 24-hour period) that was microbiologically confirmed as caused by VTEC 0157, and disease onset between 10 April and 1 May 2007. A secondary case was defined as a person with gastrointestinal illness, microbiologically confirmed as caused by VTEC 0157, who had the second or subsequent such illness in the household and whose onset of illness was two or more days after the onset of the primary case.

The first meeting of the outbreak control team (OCT) took place on 30 April 2007. The Veterinary Laboratories Agency (VLA) was subsequently asked for assistance after epidemiological enquiries identified contact with animals on an open farm (rather than a food-borne infection) as the likely source for two index cases. Neighbouring Health Protection Units were alerted about the cluster of VTEC 0157. General practitioners were alerted to report any cases of gastrointestinal illness and to send a sample for microbiological investigation. A structured questionnaire was administered per telephone to all probable cases (or to their parents) to record onset of illness and symptoms, and to explore possible risk factors such as visit to open farms and contact with animals, food and drink risk factors, travel, swimming, and close contact history.

The open farm was visited by the OCT to evaluate risks to health of staff and visitors. This was a typical open farm with ewes, lambs, goats, llamas, pigs, calves, chickens, rabbits and guinea pigs. There had been approximately 14,000 visitors to the farm during the Easter holiday period in April 2007. Environmental testing at the open farm was undertaken to evaluate possible sources of infection.

\section{Microbiological investigations}

All cases and household contacts provided stool specimens for laboratory investigation. In addition to considering isolates from the cases linked to the open farm, it was necessary to evaluate the laboratory typing of the strains from all human samples from the region to scrutinise possible links between cases. An additional 83 faecal specimens were collected from the animals on the open farm. Sampling was based on groups of animals sharing the same space, and concentrated on likely contacts: sheep, weaned and unweaned lambs, goats, kids, calves, pot-bellied pigs and pet rabbits.

Human and animal samples were cultured as described by Willshaw et al. [2] and presumptive VTEC 0157 isolates were sent for phage typing to the central Laboratory for Enteric Pathogens at the Health Protection Agency (HPA) Centre for Infections. All isolates from human and animal sources were confirmed biochemically as $E$. coli and subsequently serotyped and phage-typed. They were tested for the presence of $\mathrm{VT}_{1}$ and $\mathrm{VT}_{2}$ by polymerase chain reaction (PCR) and isolates from patients infected with the same phage type of VTEC 0157 and animal isolates from the farm were compared by pulse field gel electrophoresis (PFGE) of fragments generated by the restriction enzyme $\mathrm{Xbal}[2]$.

\section{Results}

A total of 13 confirmed cases of VTEC 0157 , one of them asymptomatic, occurred in five families in the neighbouring counties of Norfolk and Lincolnshire in April and May 2007. The epidemiological curve for the 12 symptomatic cases is shown in Figure 1. Initially no epidemiological links were established between the four Norfolk families and the incident was investigated as a temporal cluster. After the case from Lincolnshire was identified, an outbreak was declared, consisting of Family A from Norfolk (one primary and two secondary cases) and Family B from Lincolnshire (one primary case only) who had visited the open farm. A narrower case definition for the outbreak was used which included only those persons with a link to the farm. The working hypothesis was that the outbreak was caused by direct transmission from contact with animals at the farm, followed by secondary transmission within the households.

The index case from Family A had visited the farm on 9 April 2007 and developed symptoms on 13 April 2007. It is possible that Case 2 (Table 1 ) of Family $A$ is a coprimary case. She visited the farm on the 9 April 2007 and developed symptoms on 17 April 2007 (eight days later). The index case from Family $B$ visited the farm on 20 April 2007 and developed symptoms on 22 April 2007. The main risk activities were identified from the questionnaires (100\% response rate) as being bottle feeding of lambs and feeding and petting goats.

In addition to the outbreak cases, there were eight cases and one asymptomatic carrier from three other families (C, D and E) with no ascertainable links to the open farm or to Families A or B. These family groups were investigated and followed up as part of a

\section{FIGURE 1}

Cluster of verotoxin-producing E. coli O157 gastroenteritis, eastern England, April-May $2007(\mathrm{n}=12)$

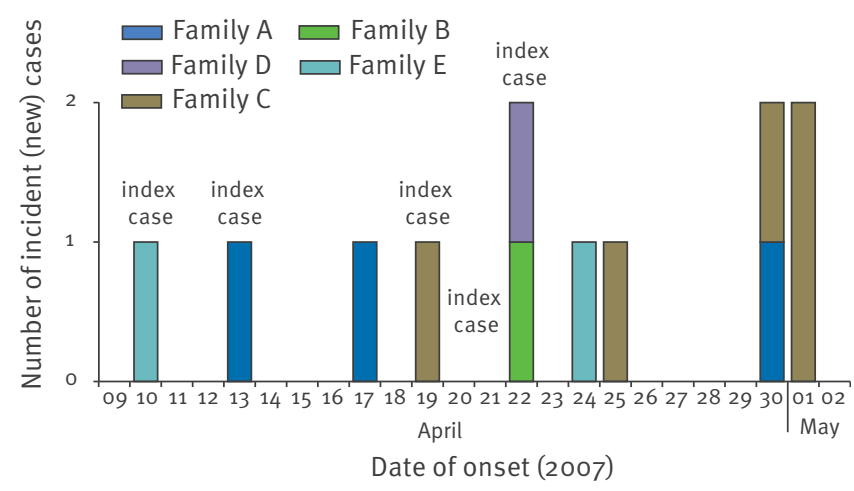




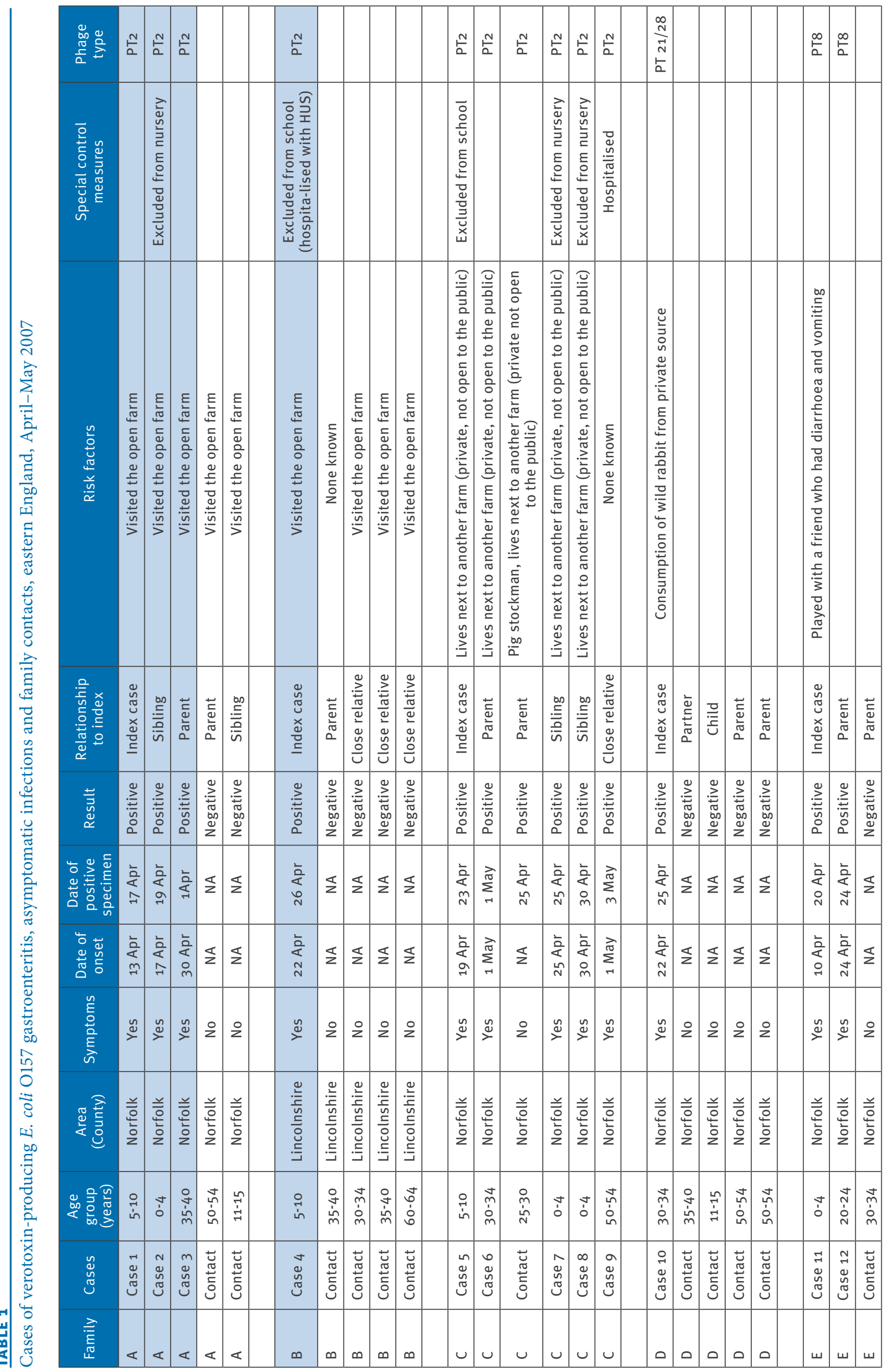


separate cluster. One of these families (C) lived next to a farm where the father worked as a pig stockman. Five members of that family developed gastroenteritis caused by the same phage type (PT2) of VTEC 0157 but with a distinct PFGE profile (Table 1). The asymptomatic carrier was also a member of Family $C$ and was found positive for the same strain of VTEC 0157 . Three of the six family members developed symptoms or were tested positive for VTEC 0157 within a period of six days (between 19 and 25 April 2007), the others later. It could be assumed that these three cases were coprimary cases and had the same environmental exposure. Environmental sampling was not done because the farm was private and it did not present risk to the public. Consumption of a wild rabbit purchased from a private source was a suspected risk factor for family D. No food specimen was available to test this hypothesis however. Possible sources of infection for family $E$ were unpasteurised cheese (which tested negative on culture) and a friend with diarrhoea and vomiting who had played with the five year-old index case.

Overall, this spatiotemporal cluster consisted of 12 laboratory-confirmed cases and one asymptomatic carrier from five families with isolates of $E$. coli 0157 (Table 1). Four of the cases were linked to the open farm (Families $A$ and $B$ ), while in eight cases and the asymptomatic carrier (Families C, D and E) there was no epidemiological link to the farm (Figure 2). Nine of the cases were children aged five months to 13 years. Five cases were hospitalised: a six year-old child from Family B was admitted with HUS, a 53 year-old secondary case from Family $\mathrm{C}$ with severe diarrhoea, and three further cases were admitted to hospital for overnight stays.

\section{Laboratory confirmation of epidemiological link with the open farm}

Veterinary investigations yielded 17 presumptive $E$. coli 0157 isolates from 83 samples taken. Fourteen isolates were from adult sheep or lambs, including lambs which had been bottle-fed by visitors. In addition, samples from one adult pig (out of three tested) and two 4-6 month-old cattle (out of 17 tested) were positive. Isolates from the two primary cases from Families $A$ and $B$ who had visited the farm and the two contacts from Family A were confirmed as E. coli 0157 phage type $\mathrm{PT}_{2}$ with genes for $\mathrm{VT}_{2}$ but not $\mathrm{VT}_{1}$. The veterinary isolates were also VTEC 0157 PT2, VT2. The PFGE profiles of the strains comprised at least 20 Xbal fragments. A single profile was seen in the isolates from three human strains and all 17 animal isolates. The profile of the isolate from the first primary case had some evidence of one additional band in the profile that was not present in the strain from his

\section{FIGURE 2}

Spread of verotoxin-producing E. coli O157 infection within households, eastern England, April-May 2007

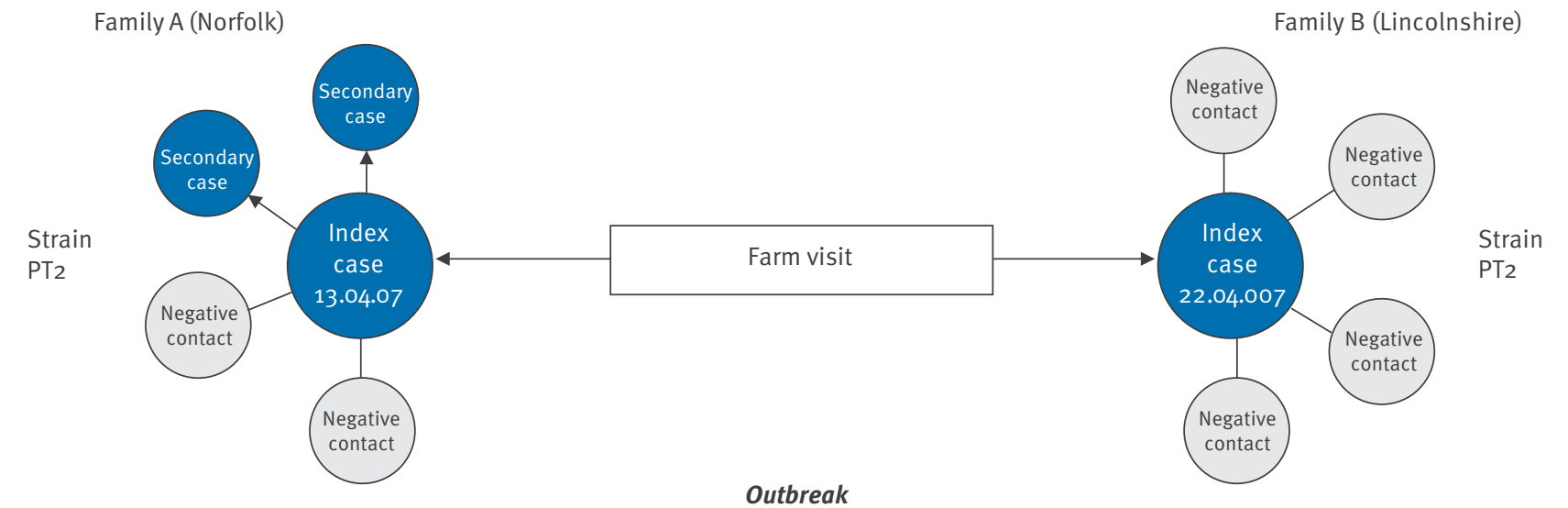

Cluster
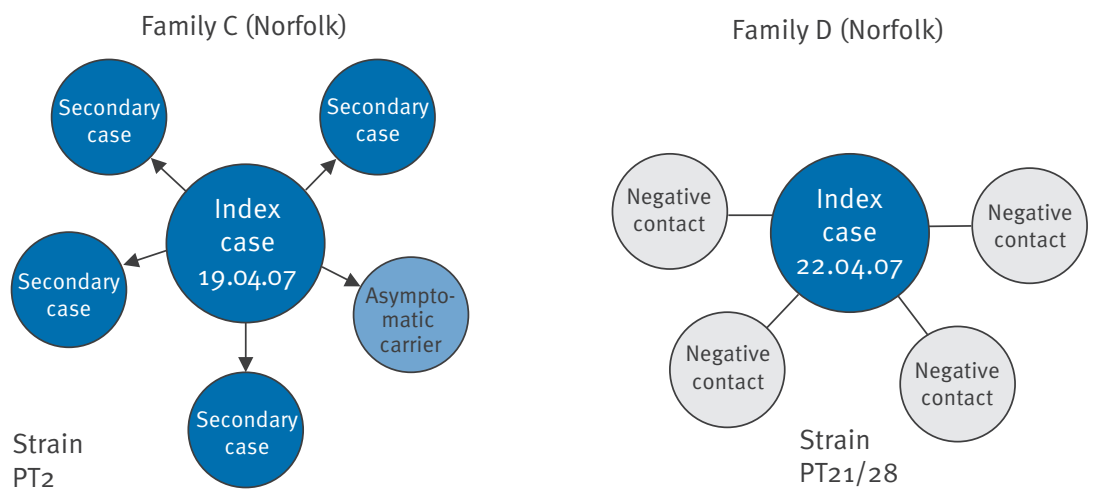

Family E (Norfolk) 
contacts (Table 2 ). The variation was not considered significant given that the strains were indistinguishable by other tests and their sources could be linked epidemiologically.

Isolates of VTEC 0157, PT2, VT2 were also confirmed in six members of Family $C$ in Norfolk. PFGE showed that the strain infecting this family differed by at least five fragment positions (out of 20) from the farm-associated cases. Evidence from the Laboratory for Enteric Pathogens database of profiles indicated that the strains were genotypically distinct from those isolated at the farm. This supported the view that these cases were not linked to the farm or to the families that visited it.

VTEC $0_{157}$ of phage types other than PT2 were isolated from the other two Norfolk families (Table 1). Two isolates from Family $\mathrm{E}$ were confirmed as belonging to PT8, VT1 and VT2. A single isolate received from Family $D$ was $P T 21 / 28, V_{2}$. Given the discrimination by phage typing, none of the isolates was examined by PFGE.

\section{Outbreak control measures}

Initial outbreak control measures were instituted as soon as an outbreak was identified and included increased surveillance by raising awareness amongst primary care staff, hospital clinicians and laboratories, and informing Health Protection Teams and

\section{TABLE 2}

Typing of isolates of verotoxin-producing E. coli O157 linked to the open farm in Eastern England, April-May 2007

\begin{tabular}{|l|c|c|c|}
\hline $\begin{array}{l}\text { Case/source of } \\
\text { specimen }\end{array}$ & $\begin{array}{c}\text { Phage } \\
\text { type }\end{array}$ & $\begin{array}{c}\text { Presence of } \\
\text { verotoxin } \\
\text { gene by } \\
\text { polymerase } \\
\text { chain reaction }\end{array}$ & $\begin{array}{c}\text { Pulse field gel } \\
\text { electrophoresis }\end{array}$ \\
\hline $\begin{array}{l}\text { Family A, index case, } \\
\text { visited farm (Case 1) }\end{array}$ & 2 & VT2 & $\begin{array}{c}\text { Profile 1 } \\
\text { (possible extra } \\
\text { small fragment; } \\
\text { not significant) }\end{array}$ \\
\hline Family A contact (Case 2) & 2 & VT2 & Profile 1 \\
\hline Family A contact (Case 3) & 2 & VT2 & Profile 1 \\
\hline $\begin{array}{l}\text { Family B, index case, } \\
\text { visited farm (Case 4) }\end{array}$ & 2 & VT2 & Profile 1 \\
\hline Empty calf house & 2 & VT2 & Profile 1 \\
\hline Calves 4-6 months-old & 2 & VT2 & Profile 1 \\
\hline Pigs & 2 & VT2 & Profile 1 \\
\hline Weaned lambs & 2 & VT2 & Profile 1 \\
\hline $\begin{array}{l}\text { Unweaned lambs } \\
\text { (2-3 months-old) }\end{array}$ & 2 & VT2 & Profile 1 \\
\hline Sheep house 1 & 2 & VT2 & Profile 1 \\
\hline Sheep house 2 & 2 & VT2 & Profile 1 \\
\hline Sheep house 3 & VT2 & Profile 1 \\
\hline
\end{tabular}

VT: verotoxin.

Source: Laboratory of Gastrointestinal Pathogens, Centre for Infections, Health Protection Agency, UK.
Environmental Health Departments and general practitioners in neighbouring counties. All cases were followed up urgently by the Environmental Health Departments for the area. Affected families were given advice regarding hygiene measures to prevent secondary cases within households.

The OCT initially considered the option of temporarily closing the farm to the public pending investigations. However, any such formal enforcement action had to be based on a risk assessment of the threat to the health of the public. It was agreed at the time that the cases in two unrelated families did not constitute a significant risk, especially in view of the large number of visitors to the farm during the perceived exposure period. Furthermore, no immediate significant risks to public health were identified during the OCT's inspection of the farm. It was therefore decided not to close the farm, but following the advice of the OCT from 30 April 2007, the farm management (who were very cooperative), took immediate measures to improve hand washing facilities and signage around the site. Separate and identifiable areas were allocated for visitors to eat and drink. Staff were briefed about the need for increased hygiene and supervision of visitors, and the petting of animals and bottle-feeding of lambs was suspended voluntarily on a temporary basis. After confirmation of positive animal specimens, access of the public to the building housing most infected animals was restricted, and the areas were emptied of livestock and cleaned and disinfected thoroughly. These immediate measures were formalised on 4 May 2007 with the issuing by the local authority of a statutory notice under the Health and Safety at Work etc Act 1974 to require that health and safety risk assessments be carried out. The farm management complied with the notice by reviewing and updating the risk assessment relating to the visitor and animal contact activity, in accordance with the Health and Safety Executive guidance [19] and implementing the additional measures identified. The newly introduced measures included improving visitor information and leaflets. No further cases of VTEC $0_{157}$ infection in visitors were reported that year.

\section{Discussion and conclusions}

Exposure to livestock on open farms continues to pose a threat to the general public and particularly to children, and a number of outbreaks have been reported from the UK [20-24]. In August and September 2009, an outbreak of E. coli 0157 at Godstone Farm in England involved 93 visitors [7]. Seventeen of the cases (all of them children) were diagnosed with HUS. A review and analysis of open farm outbreaks in England and Wales over the period 1997-2007 has been presented by Pritchard et al. [6]: VTEC $0_{157}$ was confirmed in $61.3 \%$ of the investigated premises containing animals of various species. E. coli $0_{157}$ was isolated in $17.8 \%$ of all samples, and verotoxin genes were detected by PCR in $98.4 \%$ of representative isolates. The main phage types were 2 and $21 / 28$, which were also the most common types isolated from human cases during that 10 
year period. The Health and Safety Executive guidance advises farmers to assume that their animals carry $E$. coli 0157 and to put control measures in place to minimise the risk to visitors [19]. In the outbreak in 2007 described in this paper, results of phenotypic and genotypic typing of isolates from farm visitors and livestock supported the epidemiological evidence that contact with animals or their faeces was the source of the primary infections.

In August 2008, a further case of VTEC 0157 with a link to the same open farm was reported to the Norfolk, Suffolk and Cambridgeshire HPU Norfolk office. The isolate was $\mathrm{PT}_{21 / 28}$, a different strain from the one isolated in in the outbreak in 2007 described here. The index case was a seven year-old child who had most probably acquired the infection from her 11 month-old sibling whose stool was subsequently found positive for $0_{157}$ and who had visited the open farm five days before onset of symptoms. A further site visit found that the recommendations from the previous year had been fully implemented. The only further recommendation to the farm was to additionally warn visitors that children aged two years or younger should be particularly protected, as enforcing hygiene measures and avoiding contact with the ground is particularly difficult in this age group.

This cluster of VTEC $0_{157}$ infections also highlighted the risk of person-to-person spread of infection among family members. The need for follow-up of cases and enhanced advice on hygiene measures in the households to prevent secondary transmission should be stressed, particularly since transmission can also occur from asymptomatic cases [25]. The further case in 2008 highlights the difficulty of ensuring strict hygiene in very young children. Such children are likely to have direct contact with possibly contaminated ground, and are also unlikely to be able to follow hygiene guidance. They may also be in nappies, and contact with children in nappies is a known risk factor for gastrointestinal infection [13].

Multidisciplinary collaboration among the health protection, veterinary, environmental health and laboratory services was crucial for the prompt and successful control of this cluster of VTEC 0157 infections. A particular issue faced by an OCT in this situation is the lack of clarity surrounding the availability and use of immediate formal action (if applicable) in the case of a perceived risk to the public posed by a commercial business. In this particular case, the OCT made a judgement based on an on-site assessment that the farm did not present a sufficient risk to the public to warrant temporary closure, and felt that the hazard from VTEC 0157 could be controlled by risk management procedures involving cooperation by the farm management with immediate institution of improved safety measures. The Health and Safety at Work etc Act 1974, together with the associated guidance for open farms, gives a framework for a statutory response to situations where employees and/or visitors may be exposed to risks of infection due to workplace activities. The outbreak at Godstone Farm in 2009 highlighted the importance of keeping public areas free from contamination with animal faeces, providing information to the public, and supervising children's handwashing [7].

There is a need to proactively re-assess ongoing health risks on open farms and ensure that control measures are in place at all times but particularly during peak holiday periods. Members of the public, particularly parents and children, should be kept well informed about the potential risks from zoonotic transmission of diseases such as VTEC.

It should be emphasised, however, that the risk of acquiring VTEC $0_{157}$ infection from open farms is minimal compared with other hazards of daily life and that open farms serve an important educational role and are a major contributors to the tourism and leisure industries.

\section{Acknowledgements}

We wish to thank colleagues from the local authority for their assistance and involvement in this investigation, and the laboratory staff at VLA Bury St Edmunds in culturing the animal samples, particularly Joel Handyside who assisted with the sample collection on the farm. The willing cooperation of the manager of the open farm is also acknowledged.

\section{References}

1. Caprioli A, Morabito S, Brugere H, Oswald E. Enterohaemorrhagic Escherichia coli: emerging issues on virulence and modes of transmission. Vet Res. 2005;36(3):289-311.

2. Willshaw GA, Smith HR, Cheasty T, O'Brien SI. Use of strain typing to provide evidence for specific interventions in the transmission of VTEC 0157 infections. Int J Food Microbiol. 2001;66(1-2):39-46.

3. Health Protection Agency (HPA). Vero cytotoxin-producing Escherichia coli (VTEC). Epidemiological Data on VTEC in England and Wales. London: HPA Centre for Infections; 2010. Available from: http://www.hpa.org.uk/Topics/ InfectiousDiseases/InfectionsAZ/EscherichiaColi0157/ EpidemiologicalData/

4. Health Protection Agency (HPA). Epidemiological data on VTEC in England and Wales. Regional totals of E. coli $\mathrm{O}_{157}$ in England and Wales, by year. London: HPA Centre for Infections; 2011. Available from: http://www.hpa.org.uk/web/ HPAweb\&HPAwebStandard/HPAweb_C/1249113631774

5. Department for Environment, Food and Rural Affairs (DEFRA). Zoonoses Report. United Kingdom 2008. London: DEFRA; 2010

6. Pritchard GC, Smith R, Ellis-Iversen J, Cheasty T, Willshaw GA. Verocytotoxigenic Escherichia coli $0_{157}$ in animals on public amenity premises in England and Wales, 1997 to 2007. Vet Rec. 2009;164(18):545-9.

7. Walker G. E. coli $\mathrm{O}_{157}$ - developments arising from the Griffin Committee Enquiry following the Godstone farm outbreak. Paper Number: H9/04. TRIM Ref: 2010/98084. Health and Safety Executive/Local Authority Enforcement Liaison Committee (HELA); 2010. Available from: http://www.hse.gov. uk/aboutus/meetings/committees/hela/150410/h9-04.pdf

8. E. coli 0157 infections in the UK. Euro Surveill. 2006;11(22): pii=2964. Available from: http://www. eurosurveillance.org/ViewArticle.aspx?Articleld=2964

9. Ihekweazu C, Barlow M, Roberts S, Christensen H, Guttridge B, Lewis DA, et al. Outbreak of $\mathrm{E}$. coli $\mathrm{O}_{157}$ infection in the south west of the UK: risks from streams crossing seaside beaches. Euro Surveill. 2006;11(4):pii=613. Available rom: http://www. eurosurveillance.org/ViewArticle.aspx?Articleld=613 
10. Locking ME, O’Brien SJ, Reilly WJ, Wright EM, Campbell DM, Coia JE, et al. Risk factors for sporadic cases of Escherichia coli 0157 infection: the importance of contact with animal excreta. Epidemiol Infect. 2001;127(2):215-20.

11. Health Protection Agency (HPA). Vero cytotoxin-producing Escherichia coli 0157: 2006. Health Protection Report 2007;1(32). Available from: http://www.hpa.org.uk/hpr/ archives/2007/hpr3207.pdf

12. Lynn RM, O’Brien SJ, Taylor CM, Adak GK, Chart H, Cheasty T, et al. Childhood hemolytic uremic syndrome, United Kingdom and Ireland. Emerg Infect Dis. 2005;11(4):590-6.

13. Guidelines for the control of infection with Vero cytotoxin producing Escherichia coli (VTEC). Subcommittee of the PHLS Advisory Committee on Gastrointestinal Infections. Commun Dis Public Health. 2000;3(1):14-23.

14. Griffin PM, Tauxe RV. The epidemiology of infections caused by Escherichia coli $\mathrm{O}_{157} \mathrm{H7}$, other enterohemorrhagic E. coli, and the associated hemolytic uremic syndrome. Epidemiol Rev. 1991;13:60-98.

15. Adak G, et al. Comprehensive outbreak surveillance - the key to understanding the changing epidemiology of foodborne disease. In: Noeckler K, Teufel P, Schmidt K, Weise E, editors. Proceedings of the fourth World Congress of Foodborne Infections and Intoxications (volume 1). Berlin: German institute for consumer health protection and veterinary medicine (BGVV):1998. p 211-5.

16. Taylor CM, White RH, Winterborn MH, Rowe B. Haemolyticuraemic syndrome: clinical experience of an outbreak in the West Midlands. Br Med J (Clin Res Ed). 1986;292(6534):1513-6.

17. Martin DL, MacDonald KL, White KE, Soler JT, Osterholm MT. The epidemiology and clinical aspects of the hemolytic uremic syndrome in Minnesota. N Engl J Med. 1990;323(17):1161-7.

18. Fitzpatrick MM, Shah V, Trompeter RS, Dillon MJ, Barratt TM. Long term renal outcome of childhood haemolytic uraemic syndrome. BMJ. 1991;303(6801):489-92.

19. Health and Safety Executive (HSE). Preventing or controlling ill health from animal contact at visitor attractions. Agriculture Information Sheet No 23 (revised). Sudbury: HSE; 2002. Available from: http://www.hse.gov.uk/pubns/ais23.pdf

20. Pritchard GC, Willshaw GA, Bailey JR, Carson T, Cheasty T. Verocytotoxin-producing Escherichia coli $0_{157}$ on a farm open to the public: outbreak investigation and longitudinal bacteriological study. Vet Rec. 2000;147(10):259-64.

21. Trevena WB, Willshaw GA, Cheasty T, Domingue G, Wray C. Transmission of Vero cytotoxin producing Escherichia coli $\mathrm{O}_{157}$ infection from farm animals to humans in Cornwall and west Devon. Commun Dis Public Health. 1999;2(4):263-8.

22. Payne CJ, Petrovic M, Roberts RJ, Paul A, Linnane E, Walker $M$, et al. Vero cytotoxin-producing Escherichia coli 0157 gastroenteritis in farm visitors, North Wales. Emerg Infect Dis. 2003;9(5):526-30.

23. Milne LM, Plom A, Strudley I, Pritchard GC, Crooks R, Hall $\mathrm{M}$,et al. Escherichia coli $\mathrm{O}_{157}$ incident associated with a farm open to members of the public. Commun Dis Public Health. 1999;2(1):22-6.

24. Chapman PA, Cornell J, Green C. Infection with verocytotoxinproducing Escherichia coli 0157 during a visit to an inner city open farm. Epidemiol Infect. 2000;125(3):531-6.

25. Beutin L, Kaulfuss S, Cheasty T, Brandenburg B, Zimmermann S, Gleier K, et al. Characteristics and association with disease of two major subclones of Shiga toxin (Verocytotoxin)producing strains of Escherichia coli (STEC) 0157 that are present among isolates from patients in Germany. Diagn Microbiol Infect Dis. 2002;44(4):337-46. 